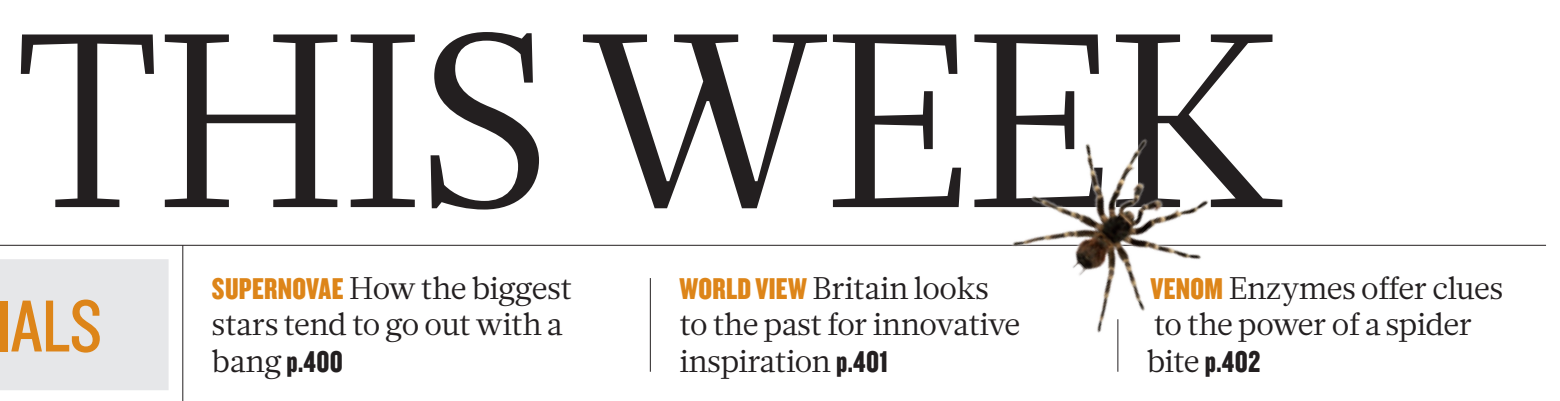

EDITORIALS stars tend to go out with a bang $\mathbf{p . 4 0 0}$

\title{
Still much to learn about mice
}

\section{A project that aims to mutate every gene in the mouse genome to improve our knowledge of mouse biology should help to avoid irreproducible results and costly failures in drug development.}

$\mathrm{T}$ The mouse is the undisputed king of laboratory science. It achieved its royal status after it was chosen as the first mammal - after the human - to have its genome sequenced. Understanding the genome made it possible to develop new molecular technologies to make mutant mice, and scientists have made them by the thousand. They have also used these mutant mice to illuminate how genes and the molecular pathways they control operate in health and disease. This has also cast some welcome, if indirect, light on human diseases.

Specialized repositories have sprung up around the world to accommodate these mutant mice and to allow them to be shared. Everybody benefits: researchers, who can have the latest mouse mutants sent to them; and science more broadly, as the repositories guarantee the quality of the genetics and the health of each strain, which is crucial for comparing the results of different experiments.

That quality must be defended. At a meeting in Munich, Germany, earlier this month, representatives of repositories from China, the United States, Europe, Japan, Canada and elsewhere expressed a concern: new technology renders it so easy to make a knockout mouse that more scientists may start to use it, without being aware of the general genetics expertise needed. It is a concern that deserves broader discussion.

At present, the ability to make a high-quality knockout of a gene in a mouse requires considerable skill in genetics and breeding techniques. But new and disruptive technologies - gene-editing methods such as CRISPR - have entered the scene, making mouse engineering considerably less challenging. But will this mean a series of strains produced with inadequate quality control? If so, experiments will be harder to reproduce, and medical research could suffer.

Since 2010, those involved with the mouse repositories, together with other geneticists, have been coordinating the International Mouse Phenotyping Consortium (IMPC). The consortium aims to make a conditional mouse mutant - in which the targeted gene can be switched off to order - for every gene in the mouse genome in a defined genetic background. Each mutant mouse will be examined in detail to find out exactly what changes occur in the animal's physiology, anatomy or behaviour when the gene is removed. It is a colossal task, with a colossal estimated price tag of US\$900 million to be shared by participating nations.

The first thousand of these phenotyped mutants will be available in a couple of months. Fifteen thousand will be available by 2021 if all goes to plan. But that plan assumes that the requisite funding will continue to flow. And like all those with power, the mouse has enemies, whose views may shake the confidence of funding agencies, already notoriously averse to large, long-term investments such as repositories. Mouse mutants are invaluable in understanding biological processes and what can go wrong in biochemical or cellular pathways in diseases such as cancer or Alzheimer's. Too often,

however, scientists consider them models of human disease, as if a manipulated gene or two could actually recapitulate a disease in a different species. Therapies that 'cure' a mutant mouse but then fail in the clinic, bring the mouse into disrepute - as recently lamented by Steven Perrin, of the Amyotrophic Lateral Sclerosis Therapy Development Institute in Cambridge, Massachusetts, who has witnessed the phenomenon too many times in relation to this disease

\section{"Therapies that 'cure' a mutant mouse but then fail in the clinic, bring the mouse into disrepute."}

(Nature 507, 423-425; 2014).

Some scientists complain that the phenotyping approach is unreliable because when different laboratories knock out the same gene, they may see different consequences - adding to the current crisis in the reproducibility of biomedical results. But the discrepancies are usually because mice in different labs are of different genetic strains; this makes a big difference to whether the function of a missing gene will be compensated for. Another cause of discrepancies can be viruses in the mice, which can change the way that genes are expressed. In fact, $12 \%$ of the strains submitted to one of the main mouse repositories, the Jackson Laboratory in Bar Harbor, Maine, are contaminated by pathogens.

This is why it is so desirable to have repositories that guard the health and genetic quality of the deposited mice. It is also why the IMPC is so important - by detailing the function of each gene in a standard genetic background, it will provide a necessary source of information for researchers for many decades, and help in the effort to ensure that biological results are reproducible. .

\section{Not on the label}

\section{A US push to flag foods as genetically engineered is hard to swallow.}

$\mathrm{T}$ he tiny US state of Vermont is no stranger to gourmands, particularly those with a fondness for its maple syrup and ice cream. On 8 May, Vermont carved out a new position in the national food scene when its governor, Peter Shumlin, signed into law a bill that requires foods on sale in the state that were made with genetically engineered ingredients to be labelled as such. It is the first such law in the country.

The law's fate is unclear: food-industry groups immediately vowed to challenge it in court. Vermont's attorney-general is readying the state's legal defence - the bill Shumlin signed included provisions to 